\title{
APEC en el debate político
}

DOI: $10.32870 /$ mycp.v4i14.142

Carlos Uscanga*

I ntroducción

Desde el nacimiento del mecanismo de Cooperación Económica Asia Pacífico (mejor conocido por sus siglas en inglés, APEC) ha estado en el centro de la atención la posibilidad de que ese importante foro no sólo se enfoque en temas comerciales, financieros y de cooperación económica y técnica, sino que también se oriente a la discusión en asuntos de carácter político e incluso de seguridad regional.

Para el sector que en forma insistente planteaba la necesidad de que el APEC rompiera la inicial reticencia para transformarse en un espacio multilateral para el tratamiento de problemas sensitivos de naturaleza no económica, los atentados del 11 de septiembre en las Torres Gemelas del World Trade Center de la ciudad de Nueva York y en el Pentágono, dieron la pauta para al pronunciamiento para que las 21 economías se unieran a la cruzada contra el terrorismo internacional durante la Cumbre Informal de Líderes dentro del marco de la reunión del APEC en Shangai, China.

Para algunos, esto marca un cambio substancial en la proyección del APEC por ser la primera vez que se manifiesta una declaración de esa naturaleza. Sin embargo, también habría que agregar que los encuentros anteriores han estado inmersos en su entorno por un debate político, y por tanto no es un elemento que haya estado exento del clima en que se han celebrado las reuniones ministeriales y la misma cumbre informal de líderes.

El siguiente ensayo tiene la finalidad de presentar, en forma general, algunas reflexiones

* Doctor en Cooperación Internacional por la Universidad de Nagoya, Japón. Miembro del Sistema Nacional de Investigadores Nivel I. Profesor-Investigador del Centro de Relaciones Internacionales de la Facultad de Ciencias Políticas y Sociales, UNAM y Profesor de Cátedra ITESM, campus ciudad de México. en torno al "debate" político en el seno de APEC, identificando los principales problemas y puntos de acuerdo entre los miembros de ese foro que agrupa a las principales economías de la Cuenca del Pacífico.

\section{De los orígenes}

Es una imprecisión apuntar que APEC, a lo largo de su corta historia, ha mantenido una asepsia sobre el tratamiento de temas políticos. Si bien es cierto que se evitó incorporar pronunciamientos de ese tipo dentro de su agenda, el entorno de su nacimiento y diversos incidentes durante las reuniones ministeriales, y en especial en las reuniones informales de los líderes, han estado marcados por intensas discusiones que impactan y cuestionan las condiciones internas de las economías anfitrionas como los temas de derechos humanos, democracia y la autodeterminación. Como ejemplo, mencionaremos las declaraciones del entonces vicepresidente estadounidense, $\mathrm{Al}$ Gore, durante la reunión APEC en 1998, cuestionando el sistema político de Malasia y apoyando en forma abierta el movimiento de reforma contra el gobierno del primer ministro Mohamad Mahathir.

Si bien fue ampliamente documentado y seguido por la prensa internacional, valdría la pena hacer notar que parece completamente olvidado que el mismo nacimiento de APEC generó distintas reacciones políticodiplomáticas. Como es sabido, la propuesta original del primer ministro de Australia Bob Hawke visualizaba la creación de un organismo de carácter gubernamental que agrupara fundamentalmente a las economías del Pacífico Asiático, con la exclusión de Estados Unidos y Canadá, que participaban en la entonces Conferencia (hoy Consejo) de Cooperación Económica del Pacífico (mejor conocido por sus siglas en inglés, PECC). 
La propuesta generó reacciones en Washington, por lo que de manera inmediata el entonces secretario de Estado, James Baker, emprendió una cruzada diplomática contra la iniciativa australiana, e incluso delineó algunos puntos para crear una contrapropuesta en la llamada "Doctrina Baker". Al final se logró su inclusión, lo que permitió la celebración de la reunión en la ciudad de Canberra a finales de 1989, con la participación de 12 economías, que fueron los miembros fundadores del APEC. ${ }^{1}$

El consenso para consolidar el trabajo del nuevo foro no fue una labor sencilla. Al principio, había una serie de cuestionamientos sobre si era necesario un nuevo mecanismo de cooperación, en tanto que el PECC podría ofrecer, al modificar sus principios de funcionamiento -en particular el referido a que los representantes de los gobiernos tuvieran representación oficial- ${ }^{2}$, lo que potencialmente podría ser un marco apropiado para impulsar el consenso político necesario para enfrentar los apremiantes problemas que los intensos procesos de i n t e r d e p e n d e n c i a económica generaban en la región, así como la amenaza proteccionista derivada de la no exitosa conclusión de la Ronda de Uruguay a principios de los noventa.

En forma paralela, el ASEAN se manifestó, sistemáticamente, en contra de la creación de un organismo regional de carácter formal por dos razones esenciales. Por un lado, el temor que minaría la influencia de ese mecanismo subregional; por el otro, la institucionalización tendería a favorecer a los miembros con mayor capacidad de influencia económica y política.

En 1990 se logró el llamado "Consenso de Kuching” en el que el ASEAN delineó las bases de participación dentro del APEC incorporando los principios de que el nuevo mecanismo tendría un carácter consultivo y las acciones adoptadas serían voluntarias, en lo que la creación de un escenario de confianza mutua permitiría la promoción de la paz y prosperidad en la región. Además, se insistía en la necesidad de que las acciones emprendidas tomaran en cuenta las diferencias de desarrollo de las economías participantes, así como se refrendaba el compromiso para evitar la conversión del APEC en un bloque económico cerrado. Al mismo tiempo, planteaba el fortalecimiento de las capacidades individuales y colectivas para la identificación de los problemas a nivel regional y la proyección de sus intereses en los foros multilaterales. Por último, planteaba la necesidad de que el ASEAN mantuviera su identidad y cohesión en el seno de un nuevo foro intergubernamental, y advertía que cualquier interno de posible institucionalización tendría que ser de manera “gradual y pragmática”. ${ }^{3}$

Los principios adoptados en Kuching son fundamentales para entender la naturaleza sui generis en la que se sustentan las bases de cooperación en el APEC. Empero, de manera paradójica, también es el punto de partida de la separación de visiones que confluyen y se anteponen entre sí. Es decir, una perspectiva que sustenta la necesidad de mantener su esencia flexible y voluntaria, en tanto que la otra, empuja hacia una mayor institucionalización en la que los compromisos logrados estén estrictamente basados en la reciprocidad y en la formalidad de los acuerdos. ${ }^{4}$

Ésta ultima logró mayor proyección cuando Estados Unidos asume la presidencia para organizar los trabajos del APEC en 1993, en la que declaró, en forma abierta, la necesidad de una mayor institucionalización para convertirlo en más operacional. ${ }^{5}$ Bajo esta lógica, se requería la celebración de acciones concretas en las que se lograran acuerdos que fueran adoptados por los miembros y refrendados por un respaldo político de alto nivel. En este contexto surge la propuesta de la 
cumbre informal de líderes cuya primera reunión en realizó en Blake Island con el Presidente William Clinton como anfitrión, cuyo legado para el APEC sería impulsar un cambio de rumbo sustancial cuyas metas se encuentran muy lejanas todavía.

\section{El Cambio de Rumbo}

El Grupo de Personas Eminentes en el que participaban académicos, miembros de APEC bajo el liderazgo de C. F. Bergsten, presentó un reporte en 1993 y otro en 1994, en el cual se planteaba la necesidad de reorientar la agenda del APEC, introduciendo la necesidad de emprender en forma más abierta un proceso de liberalización económica y una promoción de inversiones, así como buscar los mecanismos para eliminar los obstáculos y promover el mejoramiento del ambiente de negocios en la región.

Washington buscaba proyectar sus necesidades de política comercial, en la necesidad de buscar la apertura de los mercados asiáticos eliminando el "free ride" para impulsar a la industria exportadora de Estados Unidos. Para consumo de la opinión pública, se presentaba la demanda de creación de empleos para los estadounidenses, por lo que el APEC sería un canal importante para consecución de tales objetivos.

Bajo esta perspectiva, Robert A. Manning y Paula Stern, consideran que la visión estadounidense en Asia-Pacífico se sustenta en el uso de sus recursos económicos, políticos y estratégicos para mantener, en forma activa, su liderazgo y así consolidar la creación de un orden regional que armonice plenamente con sus intereses. ${ }^{6}$ No obstante, los márgenes de maniobra de su diplomacia económica han sido menores, en su interés por transparentar una mayor reciprocidad y obligatoriedad en los acuerdos adoptados. Esto se reflejó en forma clara en Bogor en 1994, cuando Indonesia presidió la reunión de altos funcionarios y la segunda cumbre informal de líderes del APEC, en la que se adoptó, bajo la presión del grupo asiático, que la liberalización económica tendría que ser diferenciada para las economías desarrolladas en el año 2010 y para las restantes en el 2020.

Los ritmos y avances para materializar lo contenido en la Declaración de Bogor han sido lentos para las prioridades comerciales estratégicas de Estados Unidos. En 1995 en Osaka se introdujo la idea de que las acciones que sustenten los procesos de liberalización tendrían que ser comprensivas, voluntarias y flexibles, en las que se acuñe el concepto de "acciones concertadas unilaterales" que para los funcionarios estadounidenses y sus contrapartes mexicanas, representan virtuales galimatías conceptuales extraídas de la imaginaria asiática carentes de funcionalidad real.

Esta aparente falta de entendimiento, se traduce en realidad una carencia de memoria de Estados Unidos (cuando le conviene a sus intereses y proyectada al pensamiento tecnócrata y pragmático de la burocracia mexicana) con relación a lo acordado en el marco del Consenso de Kuching, en el que los entonces 6 miembros del ASEAN apuntaron claramente que favorecían un proceso gradual y la necesidad de un red primaria para apuntar la esencia de la agenda del APEC, misma que inicialmente estaba sustentada en favorecer espacios de cooperación económica. La irrupción de la agenda de liberalización y promoción de inversiones distorsionó el camino emprendido por APEC, resultado contrario a la idea inicial de Washington, un proceso arduo y complejo que ha desgastado el mecanismo y ha incrementado el escepticismo sobre la viabilidad de ese foro.

\section{Reflexión final}

A lo largo este escrito se ha tratado de demostrar que el nacimiento, la consolidación y la proyección del APEC ha estado inmersa en un entorno de debates políticos que han marcado su naturaleza y su proyección como un espacio de controversia y síntesis de puntos de vista.

El frente asiático ha tenido éxito al contener las presiones de Estados Unidos para 
imponer, en forma unilateral, sus intereses estratégicos, logrando ajustarlos dentro de los marcos de funcionamiento del APEC. Esto ha sido un elemento importante que cambia el paradigma de hegemonía clásica que Washington solía ejercer en los mecanismos multilaterales, transformando una hegemonía compartida, sustentada en un sistema de pesos y contrapesos que pueden favorecer los intereses de las potencias regionales, así como a los actores subrregionales.

Es más, puede afirmarse que a pesar de la aparente "desilusión" externada por el gobierno estadounidense hacia los trabajos del APEC, es claro que no le conviene desligarse del mismo en tanto que éste se ha convertido en un espacio de vital importancia, de encuentro y negociación informal, que permite proyectar, defender e influir en acciones para dar sustento a los requerimientos básicos de política económica exterior, no sólo para la Cuenca del Pacífico sino también a nivel global.

\section{Notas}

1 Australia, Nueva Zelandia, Estados Unidos, Canadá, Japón, Corea del Sur, así como los entonces seis miembros de la Asociación de Naciones del Sudeste de Asia ( ASEAN, por sus siglas en inglés) Filipinas, Malasia, Indonesia, Tailandia, Singapur y Brunei.

2 El PECC se fundó bajo una iniciativa japonesaaustraliana en 1980; participan empresarios, académicos y funcionarios con representación no oficial, para la identificación de acciones que impulsen la cooperación económica entre los miembros.

3 Hadi Soesastro. "APEC's Contribution to Regional Security: Asean and the APEC process" en Hadi Soesastro and Anthony Bergin (editors) The Role of Security and Economic Cooperation Structures in the Asia Pacific Region. Center for Strategic and International Studies, Indonesia, 1996, pp. 25-26.

4 Algunos autores la han calificado como la visión o aproximación "Asiática" contra la "Americana” de tipo legalista.

5 Ibid. p.27.

6 Robert A. Manning and Paula Stern. "The Myth of the Pacific Community" Foreign Affairs. Vol. 73, No. 6., November-December 1994. p.92. 